\title{
A responsabilidade social empresarial como mecanismo à proteção integral de crianças e adolescentes
}

\section{The social corporate responsibility as a mechanism for the integral protection of children and adolescents}

\author{
Hertha Urquiza Baracho ${ }^{1}$ \\ Anna Karla da Silva Brisola ${ }^{2}$ \\ José da Silva Alves Junior ${ }^{3}$
}

\section{RESUMO:}

A Constituição da República Federativa do Brasil acautela que é dever do Estado, da família e da sociedade assegurar às crianças, jovens e adolescentes, com absoluta prioridade, proteção integral à luz do princípio da dignidade humana. Neste viés, sendo a sociedade corresponsável, tem-se a responsabilidade social das empresas como mecanismo à Rede de Proteção. Por tais razões, este trabalho científico buscou verificar práticas, de empresas brasileiras, pautadas na responsabilidade social empresarial à luz do Texto Constitucional e do Estatuto da Criança e do Adolescente, baseando-se em uma pesquisa exploratório-descritiva, cujo estudo analisou uma instituição bancária com ação na Bolsa de Valores de São Paulo BOVESPA, a partir de relatórios financeiros e a revisão crítica da literatura. Por fim, concluise que a responsabilidade social empresarial pode corroborar a Rede de proteção de crianças e adolescentes e acautelar direitos e garantias fundamentais destes sujeitos em desenvolvimento.

PALAVRAS-CHAVE:

Responsabilidade - Empresarial - Crianças - Adolescentes - Proteção.

\begin{abstract}
:
The Constitution of the Federative Republic of Brazil defends that it is the duty of the State, the family and the society to ensure that children, young people and adolescents full protection in the light of the principle of human dignity with absolute priority. In this bias, being the society co-responsible, one has the social responsibility of the companies as mechanism to the Protection Network. For these reasons, this scientific work sought to verify the practices of Brazilian companies, based on Corporate Social Responsibility in the light of

\footnotetext{
${ }^{1}$ Doutora em Direito pela Pontifícia Universidade Católica de São Paulo, Brasil (1993). Pós-Doutorado na Università degli Studi di Firenze, UNIFI, na área de Ciências Sociais Aplicadas Professor Associado III da Universidade Federal da Paraíba, Brasil.

${ }^{2}$ Graduação em Direito pelo Centro Universitário de João Pessoa, Brasil.

${ }^{3}$ Graduando em Direito pelo Centro Universitário de João Pessoa -UNIPÊ
} 
the Constitutional Text and the Statute of the Child and Adolescent, based on an exploratorydescriptive study, which analyzed a banking institution with stock in the São Paulo Stock Exchange - BOVESPA, based on financial reports and the critical review of the literature. Finally, it can be concluded that corporate social responsibility can corroborate the network of protection of children and adolescents and safeguard the fundamental rights and guarantees of these individuals in development.

\section{KEYWORDS:}

Responsibility - Business - Children - Adolescents - Protection. 


\section{INTRODUÇÃO}

À luz do Texto Constitucional de 1988, é dever da família, da sociedade e do Estado assegurar às crianças e aos adolescentes, com absoluta prioridade, o direito à vida, à saúde, à alimentação, à educação, ao lazer, à profissionalização, à cultura, à dignidade, ao respeito, à liberdade e à convivência familiar e comunitária.

Essa proteção integral singulariza comportamentos que deverão ser adotados pelo poder público, pela família e a sociedade como dever de colocá-los a salvo de toda forma de negligência, discriminação, exploração, violência, crueldade e opressão. Ademais, sendo a sociedade corresponsável, tem-se a responsabilidade social das empresas como mecanismo à Rede de Proteção.

O presente trabalho pretende investigar como as empresas privadas podem contribuir para o enfrentamento à transgressão dos direitos humanos de crianças e adolescentes.

Para efetivar esse desígnio, parte-se de uma análise da conduta das organizações com o processo de globalização, bem como as mudanças institucionais voltadas à função social da empresa.

Especificamente, buscou-se verificar práticas, de empresas brasileiras, pautadas na Responsabilidade Social Empresarial à luz do Texto Constitucional e do Estatuto da Criança e do Adolescente, enaltecendo a consecução do princípio da dignidade da pessoa humana e reconhecendo a condição peculiar de desenvolvimento de crianças e adolescentes.

Trata-se de uma pesquisa exploratório-descritiva, cujo estudo analisou uma instituição bancária com ação na Bolsa de Valores de São Paulo - BOVESPA, a partir de relatórios financeiros, com o escopo de averiguar ações de responsabilidade social empresarial concernente a crianças e adolescentes.

Por fim, concluiu-se que a responsabilidade social empresarial pode corroborar a Rede de proteção de crianças e adolescentes com ações efetivas e práticas capazes de gerar impactos positivos na violação de direitos e garantias individuais dos sujeitos em desenvolvimento.

\section{A EVOLUÇÃO DA FUNÇÃO SOCIAL DA EMPRESA E AS MUDANÇAS INSTITUCIONAIS}


O sistema econômico experimentou profundas transformações no decorrer do tempo, e, a partir de tais transformações verificou-se a necessidade de remodelar a estrutura social empresarial.

Preliminarmente, tem-se a crise do sistema feudal como precursor desse processo evolutivo, tendo em vista o desenvolvimento de técnicas que impulsionaram as relações comerciais, o ressurgimento das cidades, a descentralização do poder dos senhores feudais, e a expansão das feiras comerciais a partir do sistema mercantilista.

Por conseguinte, com o crescimento industrial, culminando com a Revolução Industrial, foi possível o desenvolvimento e amadurecimento de um novo sistema econômico: o capitalismo.

Leonardo Vizeu" define o capitalismo como um "sistema econômico cujas relações de produção estão alicerçadas na propriedade privada dos bens em geral, fatores de produção e ampla liberdade de iniciativa, concorrência e contratação de mão de obra".

A expansão do sistema capitalista, bem como a Revolução Industrial, constituem acontecimentos importantes para a humanidade. Conforme Padilha e Vechia:

\begin{abstract}
As profundas transformações na Europa acompanham o declínio do modo de produção feudal e sua progressiva substituição pelo modo de produção capitalista. $\mathrm{O}$ crescimento do comércio fez nascer uma nova classe formada por ricos comerciantes - a burguesia. As Reformas protestantes confrontam o poder e a hegemonia da Igreja e do Papa. O feudalismo agoniza. As grandes navegações, o mercantilismo, a acumulação de riqueza na Europa criam as condições históricas para o desenvolvimento do novo modo de produção. O trabalho artesanal vai sendo, progressivamente, substituído pelo trabalho dividido. $\mathrm{O}$ artesão se transforma em assalariado. A burguesia, agora dona dos meios de produção, alcança poder econômico e, confronta as estruturas do "velho regime". O capitalismo nascente transforma a vida em sociedade e demanda novas formas de organização do Estado ${ }^{5}$.
\end{abstract}

Todavia, o sistema capitalista voltando à maximização do lucro acentuou sobremaneira o labor humano, priorizando o capital frente às resistências físicas $\mathrm{e}$ psicológicas dos trabalhadores, e instaurando um processo econômico exploratório.

${ }^{4}$ FIGUEIREDO, Leonardo Vizeu. Lições de Direito Econômico. $7^{\mathrm{a}}$ ed, versão eletrônica. Rio de Janeiro: Editora GEN, 2014, p. 70.

${ }^{5}$ PADILHA, Norma Sueli; VECHIA, Rosangela. Direito de propriedade e função social da propriedade: os desafios propostos pelo estatuto da cidade.Disponível em: <http://www.publicadireito.com.br/conpedi/manaus/arquivos/anais/campos/rosangela_vecchia.pdf. $>$ Acesso em 23 mar. 2018, p. 2-3. 
Segundo Reinaldo Dias 6 “o desenvolvimento da Responsabilidade Social recebeu forte influência da globalização econômica e da repercussão dos inúmeros casos de desgoverno empresarial que marcaram o final do século $\mathrm{XX}$, favorecendo o maior envolvimento empresarial com questões sociais e ambientais".

Ademais, o supracitado autor entende que a mudança de postura empresarial se tornou um movimento estrutural da empresa, isto é, um movimento cultural que está em seu início e que apresenta um novo tipo do sistema empresarial. Nesse diapasão, Machado Filho ${ }^{7}$ defende que tal postura parte da percepção de que o exercício da responsabilidade social pode trazer retornos à empresa.

Ocorre que essa transformação de atuação é fruto do Estado de bem-estar social que se desenvolve a partir de lutas contra o Estado Absoluto, se transpondo para a proteção dos direitos e garantias fundamentais, acautelando, dentre inúmeros direitos, a função social da propriedade. Desta forma, Leonardo Vizeu ${ }^{8}$ preleciona:

\begin{abstract}
A função social da propriedade cuida da socialização desses direitos individuais, de cunho privatista, na qual o uso e a fruição da propriedade privada passam a ser condicionados ao atendimento de um objetivo maior, previamente estipulado em lei, cuja inobservância legitima a interferência do Estado sob a esfera de domínio privado do proprietário, podendo acarretar, inclusive, a expropriação do bem.
\end{abstract}

Outrossim, com a intervenção do Estado no domínio econômico possibilitou-se a edição de um arcabouço legislativo que impôs aos grupos empresariais uma atuação que colabore com o desenvolvimento social. Conforme Reinaldo Dias ${ }^{9}$ :

O verdadeiro motor da responsabilidade social nos últimos anos é que muitas empresas compreenderam que suas estratégias num ambiente global não podem se basear na degradação ambiental, nem no desrespeito às cláusulas sociais, nem na resistência ao cumprimento de normas internacionais em matéria de direitos humanos, mas que ao contrário, é o entendimento das exigências da sociedade o que incrementa a competitividade, pois incorpora padrões de excelência que cada vez mais são levados em consideração pelos consumidores, reforçando junto esses setores sua reputação corporativa, ativo intangível que não pode ser replicado por concorrentes ${ }^{10}$.

${ }^{6}$ DIAS, Reinaldo. Responsabilidade social: fundamentos e gestão. São Paulo: Atlas, 2012, p. 17.

7 MACHADO FILHO, Cláudio Pinheiro. Responsabilidade Social e governança: o debate e as Implicações. São Paulo: Cengace Learning, 2006, p. 14.

${ }^{8}$ FIGUEIREDO, Leonardo Vizeu. Lições de Direito Econômico. $7^{\mathrm{a}}$ ed, versão eletrônica. Rio de Janeiro: Editora GEN, 2014, p. 99.

${ }^{9}$ DIAS, Reinaldo. Responsabilidade social: fundamentos e gestão. São Paulo: Atlas, 2012, p. 5. 
Assim, a função social das empresas converge para uma resposta às necessidades sociais, ambientais, econômicas, de boa-governança etc., enaltecendo o supraprincípio da dignidade humana.

Neste ínterim, a Organização das Nações Unidas $(\mathrm{ONU})^{11}$, com o intuito de mobilizar lideranças empresariais da comunidade internacional, lançou um documento intitulado "Os Dez Princípios do Pacto Global", partindo do pressuposto de que hodiernamente as empresas têm exercido papel fundamental no desenvolvimento social das nações e cuja responsabilidade na sociedade é inexorável:

\begin{abstract}
1. As empresas devem apoiar e respeitar a proteção de direitos humanos reconhecidos internacionalmente; 2. Assegurar-se de sua não participação em violação destes direitos; 3. As empresas devem apoiar a liberdade de associação e o reconhecimento efetivo do direito à negociação coletiva; 4 . A eliminação de todas as formas de trabalho forçado ou compulsório; 5. A abolição efetiva do trabalho infantil; 6. Eliminar a discriminação no emprego; 7. As empresas devem apoiar uma abordagem preventiva aos desafios ambientais; 8 . Desenvolver iniciativas para promover maior responsabilidade ambiental; 9. Incentivar o desenvolvimento e difusão de tecnologias ambientalmente amigáveis; 10 . As empresas devem combater a corrupção em todas as suas formas, inclusive extorsão e propina. (grifos nossos).
\end{abstract}

No contexto geral, é imprescindível a observância do conceito de Responsabilidade Social, pelas empresas, com o escopo de reduzir os impactos negativos da atividade empresarial na comunidade e no meio ambiente.

No Brasil, com a finalidade de incentivar as mudanças institucionais voltadas à responsabilidade social da empresa, vários selos e certificações foram criados nos últimos anos com o intuito de incentivar as empresas aprimorarem sua relação com a sociedade.

Por tais razões, esse novo modelo empresarial pode constituir uma ferramenta no enfrentamento à transgressão dos direitos humanos de crianças e adolescentes à luz do princípio da proteção integral destes sujeitos em desenvolvimento, nos termos do Texto Constitucional.

\title{
3 A RESPONSABILIDADE SOCIAL DA EMPRESA E O ORDENAMENTO JURÍDICO BRASILEIRO
}

\footnotetext{
${ }^{11}$ ORGANIZAÇÃO DAS NAÇÕES UNIDAS. Os dez princípios do Pacto Global. Disponível em: <http://pactoglobal.org.br/> Acesso em: 29 set. 2018.
} 
O constituinte de 1988 preocupou-se em disciplinar acerca desta matéria e instituiu um título voltado à ordem econômica acautelando um rol de princípios que regem o sistema econômico do Estado, dentre os quais a função social da propriedade:

\begin{abstract}
Art. 170. A ordem econômica, fundada na valorização do trabalho humano e na livre iniciativa, tem por fim assegurar a todos existência digna, conforme os ditames da justiça social, observados os seguintes princípios:

$[\ldots]$

III - função social da propriedade; (grifos nossos).
\end{abstract}

Ocorre que "a evolução das relações de produção e a necessidade de propiciar melhores condições de vida aos trabalhadores, bem como o mau uso dessa liberdade e a falácia da "harmonia natural dos interesses" do Estado Liberal, fizeram surgir mecanismos condicionantes da iniciativa privada, em busca da realização de justiça social ${ }^{12}$ ".

Todavia, faz-se mister elucidar que o princípio da função social da propriedade não se esgota no supracitado título, constituindo, ainda, cláusula pétrea da Constituição Federativa do Brasil, conforme insculpido em seu art. $5^{\circ}$, inciso XXIII: “a propriedade atenderá a sua função social".

Conforme se depreende, o princípio da função social da propriedade está profundamente ligado à função social da empresa. Nessa seara, Eros Roberto Grau ${ }^{13}$ afirma que:

Constituição do Brasil de 1988 projeta um Estado desenvolto e forte, o quão necessário seja para que os fundamentos afirmados no seu art. $1^{\circ}$ e os dispositivos definidos no art. $3^{\circ}$ venham a ser plenamente realizados, garantindo-se tenha por fim, a ordem econômica, assegurar a todos existência digna.

Por sua vez, Leonardo Vizeu ${ }^{14}$ preleciona que "a função social da propriedade cuida da socialização desses direitos individuais, de cunho privatista, na qual o uso e a fruição da

\footnotetext{
12 DA SILVA, José Afonso. Curso de Direito Constitucional Positivo - $37^{\circ}$ Ed, revista e atualizada até a Emenda Constitucional n. 76, de 28.11. 2013. São Paulo: Edita Malheiros, 2014, p. 806.

${ }^{13}$ GRAU, Eros Roberto. A Ordem Econômica na Constituição de 1988. São Paulo, Malheiros: 2007, p. 101.

${ }^{14}$ FIGUEIREDO, Leonardo Vizeu. Lições de Direito Econômico. $7^{\mathrm{a}}$ ed. Rio de Janeiro: Editora GEN, 2014 , p. 99.
} 
propriedade privada passam a ser condicionados ao atendimento de um objetivo maior ${ }^{15}$ ". É como direito fundamental que a propriedade recebe total controle pelo Estado, sendo regulada, também, nos preceitos infraconstitucionais.

O Código Civil brasileiro em seu art. 1.228, $\S 1^{\circ}$ salvaguardou que o direito de propriedade que deve ser exercido em consonância com suas finalidades econômicas e sociais de modo que sejam preservados, de conformidade com o estabelecido em lei especial, à flora, a fauna, as belezas naturais, o equilíbrio ecológico e o patrimônio histórico e artístico, bem como evitada a poluição do ar e das águas.

Igualmente, o Enunciado $n^{\circ} 53$ do Conselho da Justiça Federal (CJF) estatuiu que se deve levar em consideração o princípio da função social na interpretação das normas relativas à empresa.

Nessa seara, o princípio da função social da empresa, "impõe o cumprimento simultâneo das responsabilidades econômicas, legais, éticas e filantrópicas ${ }^{16 "}$. A responsabilidade social da empresa acautelada na Constituição - extensão do princípio da função social da propriedade postula que a atividade empresarial deve estar alicerçada em um elemento de economia coletiva. Destarte, garante o cumprimento de garantias constitucionais valorizando os fins sociais a partir de uma economia capitalista.

Portanto, o Estado brasileiro preocupou-se em incentivar o exercício da empresa instituindo uma economia de livre iniciativa, mas impôs que a vontade do agente não é absoluta, devendo observância à função da propriedade com vistas a acautelar o desenvolvimento sociocoletivo.

\section{O PRINCÍPIO DA PROTEÇÃO INTEGRAL E A TUTELA CONSTITUCIONAL E INFRACONSTITUCIONAL}

Sabe-se que a carta Magna disciplinou em seu Título VIII desdobramentos jurídicos acerca da Ordem Social. Desta forma, direitos como seguridade social, saúde, previdência social, assistência social, educação, cultura, ciência e tecnologia, comunicação, meio ambiente, bem como proteção à família e aos índios foram preceituados pelo Constituinte.

16 BARBIERI, José Carlos; CAJAZEIRA, Jorge Emanuel. Reis. Responsabilidade social empresarial e empresa sustentável.São Paulo: Saraiva, 2016, pp. 10; 55. 
Consoante Barreto ${ }^{17}$, “os objetivos da ordem social são assegurar o bem-estar social das pessoas e promover a justiça social, mediante a fixação de um conjunto de medidas protetivas e prestacionais voltadas, sobretudo, ao atendimento dos setores mais necessitados da população brasileira".

Especificamente, voltou sua proteção às crianças, adolescentes e jovens no Capítulo VII do supratranscrito título reconhecendo a condição peculiar destes sujeitos em desenvolvimento, e acautelando proteção especial.

Conforme inserto no art. 227 do Texto Constitucional, é dever da família, da sociedade e do Estado assegurar à criança, ao adolescente e ao jovem, com absoluta prioridade, o direito à vida, à saúde, à alimentação, à educação, ao lazer, à profissionalização, à cultura, à dignidade, ao respeito, à liberdade e à convivência familiar e comunitária, além de colocá-los a salvo de toda forma de negligência, discriminação, exploração, violência, crueldade e opressão.

Nessa vertente, o Estado deve promover programas de assistência integral à saúde da criança, do adolescente e do jovem, admitida a participação de entidades não governamentais, mediante políticas públicas específicas voltadas a essas pessoas (art. $\left.227, \S 1^{\circ}\right)$.

Além disso, faz-se necessário dizer que a tutela integral acautelada na Constituição Federal parte da assinatura, pelo Brasil, da Convenção Sobre os Direitos da Criança, aprovada pela Organização das Nações Unidas em 1989, que preceitua:

\begin{abstract}
Artigo 3. 1. Todas as ações relativas às crianças, levadas a efeito por instituições públicas ou privadas de bem estar social, tribunais, autoridades administrativas ou órgãos legislativos, devem considerar, primordialmente, o interesse maior da criança. 2. Os Estados Partes se comprometem a assegurar à criança a proteção e o cuidado que sejam necessários para seu bem-estar, levando em consideração os direitos e deveres de seus pais, tutores ou outras pessoas responsáveis por ela perante a lei e, com essa finalidade, tomarão todas as medidas legislativas e administrativas adequadas. 3. Os Estados Partes se certificarão de que as instituições, os serviços e os estabelecimentos encarregados do cuidado ou da proteção das crianças cumpram com os padrões estabelecidos pelas autoridades competentes, especialmente no que diz respeito à segurança e à saúde das crianças, ao número e à competência de seu pessoal e à existência de supervisão adequada ${ }^{18}$.
\end{abstract}

Igualmente, disciplinou o dispositivo legal da Lei $n^{\circ}$ 8.069/90 salvaguardando que a criança e o adolescente gozem de todos os direitos fundamentais inerentes à pessoa humana,

${ }^{17}$ BARRETO, Alex Muniz. Direito Constitucional Positivo - $1^{\circ}$ Ed. São Paulo: CL EDIJUR, 2013, p. 619.

${ }^{18}$ BRASIL. Convenção sobre os Direitos da Criança. Disponível em: <http://www.planalto.gov.br/ccivil 03/decreto/1990-1994/d99710.htm>. Acesso em 23 de mar. de 2018. 
sem prejuízo da proteção integral de que trata esta Lei, assegurando-lhes, por lei ou por outros meios, todas as oportunidades e facilidades, a fim de lhes facultar o desenvolvimento físico, mental, moral, espiritual e social, em condições de liberdade e de dignidade.

Observa-se que a tutela constitucional e infraconstitucional asseverou o princípio da proteção integral como norte para elaboração do ordenamento jurídico voltado à tutela dos direitos e garantias fundamentais das crianças, jovens e adolescentes.

Cury, Garrido e Marçura ${ }^{19}$ preceituam que o princípio da proteção integral fundamenta-se na concepção de que crianças e adolescentes são sujeitos de direitos frente à família, à sociedade, e ao Estado.

Segundo lapidar abordagem de Alexandre Muniz Barreto, ${ }^{20} \mathrm{o}$ direito à proteção especial das crianças, adolescentes e dos jovens compreenderá os seguintes aspectos:

a) idade mínima de quatorze anos para o exercício de atividades laborativas (art. $7^{\circ}$, XXXIII); b) garantia de direitos previdenciários e trabalhistas; c) garantia do acesso do trabalhador adolescente e jovem à escola; d) garantia do pleno e formal conhecimento da atribuição de ato infracional, igualdade na relação processual e defesa técnica por profissional habilitado, segundo dispuser a legislação tutelar específica; e) obediência aos princípios de brevidade, excepcionalidade e respeito à condição peculiar de pessoa em desenvolvimento, quando da aplicação de qualquer medida privativa de liberdade; f) estímulo do Poder Público, através de assistência jurídica, incentivos fiscais e subsídios, nos termos da lei, ao acolhimento, sob a forma de guarda, de criança ou adolescente órfão ou abandonado; g) implantação de programas de prevenção e atendimento especializado à criança, ao adolescente e ao jovem dependente de entorpecentes e drogas afins (art. 227, $\S 3^{\circ}$ ).

Assim, é dever de todos prevenirem a ocorrência de ameaça ou violação dos direitos da criança e do adolescente. Essa proteção integral singulariza comportamentos que deverão ser adotados pelo poder público, pela família e a sociedade como dever de colocá-los a salvo de toda forma de negligência, discriminação, exploração, violência, crueldade e opressão. Ademais, sendo a sociedade corresponsável, tem-se a responsabilidade social das empresas como instrumento da Rede de Proteção.

\section{INICIATIVAS SOCIAIS COMO MECANISMO DA REDE DE PROTEÇÃO INTEGRAL DE CRIANÇAS E ADOLESCENTES}

19 CURY, Munir; PAULA, Paulo Afonso Garrido de; MARÇURA, Jurandir Norberto. Estatuto da criança e do adolescente anotado. $3^{\mathrm{a}}$ ed. São Paulo: Revista dos Tribunais, 2002, p. 21.

${ }^{20}$ BARRETO, Alex Muniz. Direito Constitucional Positivo - $1^{\circ}$ Ed. São Paulo: CL EDIJUR, 2013, p. 676. 
No Brasil, ações de responsabilidade social por empresas privadas vêm corroborando a efetivação da tutela de proteção integral de crianças, jovens e adolescentes, salvaguardada no Texto Constitucional e infraconstitucional.

Neste viés, a presente pesquisa analisou uma instituição bancária com ações na Bolsa de Valores de São Paulo (BOVESPA), a partir de relatórios financeiros, com o escopo de averiguar ações de responsabilidade social empresarial concernente a crianças e adolescentes.

Constatou-se que há iniciativas da instituição bancária, organização privada, voltadas aos Fundos de Direitos da Criança e do Adolescente (FIA) destinadas a projetos sociais, beneficiando crianças e adolescentes em situação de vulnerabilidade social, sendo os recursos geridos pelo Conselho Nacional, Estaduais e Municipais dos Direitos da Criança e do Adolescente.

O supracitado Fundo de Direitos da Criança e do Adolescente parte de uma política de atendimento mediante um conjunto articulado de ações governamentais e não governamentais realizados pela União, Estados, Distrito Federal e Municípios, nos termos do art. 88, inciso IV, da Lei ${ }^{\circ} 8.069 / 90$.

Conforme relatório disponibilizado no site da BOVESPA, “desde 2007, já destinou cerca de R\$ 7,9 milhões ao FIA, beneficiando cerca de 158 projetos e aproximadamente 18.850 crianças e adolescentes de baixa renda ${ }^{21}$ ".

O engajamento da instituição bancária com os fins sociais e a proteção integral destes sujeitos em desenvolvimento têm aportado, ainda, na formação e ampliação de uma rede cidadã que, desde 2008, vem promovendo campanhas com colaboradores, clientes e parceiros, com o escopo de incentivar destinações ao Fundo de Direitos da Criança e do Adolescente. Em 2015, a supratranscrita campanha possibilitou a arrecadação de cerca de R\$ 372 mil reais.

Além disso, constataram-se investimentos sociais e culturais, como a criação de centros que trabalham de forma integrada nas regiões da grande Fortaleza, Cariri Cearense e Alto Sertão da Paraíba. Os centros culturais permitem o desenvolvimento de crianças e adolescentes a partir do acesso à cultura universal, nacional e regional.

Ademais, através do incentivo ao esporte, há iniciativas em favor de projetos sociais que utilizem o esporte como instrumento de inclusão social de crianças e adolescentes. Em 2015, a instituição bancária beneficiava cerca de 8.264 crianças em situação de risco e

21 BOVESPA. 2015 - Relatório Anual de Sustentabilidade. Disponível em: $<$ https://www.bnb.gov.br/documents/320335/1010052/Relat\%C3\%B3rio+de+Sustentabilidade+2015 interne t/d6a1507c-b505-cf50-64e5-1d56818f55ca>. Acesso em 24 de mar. 2018. 
vulnerabilidade social, apoiando cinco projetos de natureza esportiva com um investimento de $\mathrm{R} \$ 1,3$ milhão de reais.

Verificou-se, ainda, que desde 2009, em observância à Lei de Incentivo ao Esporte (Lei 11. 438/2006), a organização já apoiou 38 projetos esportivos, beneficiando cerca de 25.900 crianças e adolescentes de baixa renda, com um investimento que ultrapassou a marca de R \$ 6,9 milhões de reais. Confirmando assim, a importância das empresas na Rede de proteção às crianças e adolescentes.

\section{CONSIDERAÇÕES FINAIS}

Com o desenvolvimento do Estado Social e, por conseguinte, a intervenção do Estado na economia, verificou-se a necessidade de restaurar a estrutura social empresarial. Neste viés, a partir da função social da propriedade, as empresas iniciaram uma mudança de postura que contribuiu para reduzir os impactos negativos da atividade empresarial na comunidade e no meio ambiente.

Desse modo, a presente pesquisa buscou investigar como as empresas privadas podem contribuir para o enfrentamento a transgressão dos direitos humanos de crianças e adolescentes, pautadas na Responsabilidade Social Empresarial à luz do Texto Constitucional e do Estatuto da Criança e do Adolescente.

O Texto Constitucional de 1988 estatuiu como dever da família, da sociedade e do Estado assegurar às crianças e aos adolescentes, com absoluta prioridade, o direito à vida, à saúde, à alimentação, à educação, ao lazer, à profisssionalização, à cultura, à dignidade, ao respeito, à liberdade e à convivência familiar e comunitária.

Neste ínterim, observou-se que ações de Responsabilidade Social Empresarial que permitem o acesso de crianças, jovens, e adolescentes à educação, à cultura, ao lazer, ao esporte etc., vêm sendo desenvolvidas por uma instituição financeira corroborando o desejo do Constituinte de 1988 ao salvaguardar o princípio da proteção integral aos sujeitos em desenvolvimento e instituir a sociedade como corresponsável deste desígnio.

Igualmente, verificou-se que as empresas têm colaborado com a Rede de Proteção integral da criança e do adolescente através de investimentos Fundos de Direitos da Criança e do Adolescente (FIA), que garante neutralidade, pois não vincula que determinada sociedade só priorize uma região e transparência, porque é possível demonstrar os dados das financiadoras, de acordo ao que foi demonstrado em números ao longo do texto. 
Logo, percebe-se a importância que o FIA representa, pois ele colabora na concretização do princípio da solidariedade, expresso tanto no art. $3^{\circ}$ da Constituição de 1988 , como mais especificadamente no art. 227 que refere às crianças e mais ainda, com a dignidade da pessoa humana, fundamento da República Federativa do Brasil.

Por tais razões é que se chegou a conclusões pontuais e específicas de que a responsabilidade social empresarial pode fortalecer a Rede de proteção de crianças e adolescentes com ações efetivas e práticas capazes de gerar impactos positivos contra a violação de direitos e garantias individuais dos sujeitos em desenvolvimento.

\section{REFERÊNCIAS BIBLIOGRÁFICAS}

ARAÚJO, Margareti Panerai (org). Construindo o social através da Ação e da Responsabilidade. Novo Hamburgo: Feevale, 2006.

BARBIERI, José Carlos; CAJAZEIRA, Jorge Emanuel. Reis. Responsabilidade social empresarial e empresa sustentável.São Paulo: Saraiva, 2016.

BARRETO, Alex Muniz. Direito Constitucional Positivo - $1^{\circ}$ Ed. São Paulo: CL EDIJUR, 2013.

BASTOS, Celso Ribeiro. Curso de Direito Constitucional. São Paulo: Saraiva , 2000.

BERCOVICI, Gilberto. Constituição econômica e desenvolvimento: uma leitura a partir da Constituição de 1988. São Paulo: Malheiros, 2005.

BOVESPA. 2015 - Relatório Anual de Sustentabilidade. Disponível em:<https://www.bnb.gov.br/documents/320335/1010052/Relat\%C3\%B3rio+de+Sustentabili dade+2015_internet/d6a1507c-b505-cf50-64e5-1d56818f55ca>. Acesso em 24 de mar. 2018.

BRASIL. Convenção sobre os Direitos da Criança. Disponível em: <http://www.planalto.gov.br/ccivil_03/decreto/1990-1994/d99710.htm>. Acesso em 23 de mar. de 2018.

BUENO, Wilson da Costa. Comunicação Empresarial: teoria e pesquisa. São Paulo: Manole, 2016.

CARVALHO, Maria de Lourdes. A Empresa Contemporânea: sua função Social em face da pessoa com deficiência. DelRey: Belo Horizonte, 2012

CURY, Munir; PAULA, Paulo Afonso Garrido de; MARÇURA, Jurandir Norberto. Estatuto da criança e do adolescente anotado. $3^{\mathrm{a}}$ ed. São Paulo: Revista dos Tribunais, 2002. 
DA SILVA, José Afonso. Curso de Direito Constitucional Positivo - $37^{\circ}$ Ed, revista e atualizada até a Emenda Constitucional n. 76, de 28.11. 2013. São Paulo: Edita Malheiros, 2014.

DEL MASSO, Fabiano. Direito Econômico Esquematizado. 4a ed. São Paulo: Método, 2016.

DIAS, Reinaldo. Responsabilidade social: fundamentos e gestão. São Paulo: Atlas, 2012.

ETHOS. Práticas Empresariais de Responsabilidade Social: Relações entre os Princípios do Global Compact e os Indicadores Ethos de Responsabilidade Social. São Paulo, 2003. Disponível em: http:<https://www3.ethos.org.br/wp-content/uploads/2012/12/18.pdf> Acesso: 29 set. 2018.

FALLER, Maria Helena Ferreira Fonseca. Função Social da Empresa e Economia de Comunhão: um encontro à luz da Constituição. Curitiba: Juruá, 2013.

FIGUEIREDO, Leonardo Vizeu. Lições de Direito Econômico. $7^{\mathrm{a}}$ ed, versão eletrônica. Rio de Janeiro: Editora GEN, 2014.

FRIEDMAN, Milton. Capitalismo e Liberdade. 2. ed. São Paulo: Nova Cultural, 1985. Apud TENORIO, F. G. e colaboradores. Responsabilidade Social e Empresarial: Teoria e prática. 1. ed. Rio de Janeiro: FGV, 2004.

GRAU, Eros Roberto. A Ordem Econômica na Constituição de 1988. São Paulo, Malheiros: 2007.

LOPES, Ana Frazão de Azevedo. Empresa e propriedade - função social e abuso de poder econômico. São Paulo: Quartier Latin, 2006.

MACHADO FILHO, Cláudio Pinheiro. Responsabilidade Social e governança: o debate e as Implicações. São Paulo: Cengace Learning, 2006.

ORGANIZAÇÃO DAS NAÇÕES UNIDAS. Os dez princípios do Pacto Global. Disponível em:<http://pactoglobal.org.br/> Acesso em: 29 set. 2018.

PEREIRA, Henrique Viana; MAGALHÃES, Rodrigo Almeida. A Função Social da Empresa e o Direito Penal Empresarial. Belo Horizonte: Arraes, 2014.

PONCHIROLLI, Osmar. Ética e Responsabilidade Social. Curitiba: Juruá, 2010.

DA SILVA, José Afonso. Curso de direito constitucional positivo. 19. ed. São Paulo: Malheiros Editores, 2001.

TAVARES, André Ramos. Direito Constitucional econômico. 2. ed. São Paulo: Método, 2006.

Submetido em: 23/10/2018

Aceito em: 23/02/2019 